\title{
Research on Multi - objective Programming in Aerobics Teaching
}

\author{
Yang Long \\ Xi'an Fanyi University, Department of Physical Education, Xi'an 710105, Shaanxi, China
}

Keywords: Multi - objective planning, Aerobics, Sports; Society, Teaching.

\begin{abstract}
With the advent of the national fitness era, physical exercise has become an indispensable part of the mass life of our country. As a school, the establishment of aerobics courses can effectively attract students' interest in sports courses that require a lot of physical strength. Students through aerobics to understand sports, to understand sports, healthy exercise, for the community to develop physical fitness and cultural quality of the comprehensive talents. This paper begins with a brief analysis of the problems in the current aerobics teaching work and the importance of implementing multi-objective planning in aerobics teaching. On this basis, the author puts forward a few ways to develop the current aerobics teaching Opinions and suggestions aimed at enriching the methods and methods of aerobics teaching, in the limited teaching time for students to bring unlimited gains.
\end{abstract}

\section{Introduction}

At present, multi-objective planning as a highly efficient management tool has been widely used in the fields of engineering, portfolio selection and so on. In the aerobics teaching, through the implementation of multi-objective planning can make teachers within a limited classroom time to take into account the quality of the students in many aspects of training, high efficiency of the students to improve the level of aerobics up to achieve the desired teaching effect The

\section{Problems in the Current Aerobics Teaching}

First of all, the goal of aerobics teaching should not only let students learn a few aerobics movements, but through systematic, scientific aerobics teaching, training students, including teamwork ability, aesthetic ability, including a variety of qualities. At present, many aerobics teachers can not correctly understand the value of aerobics can bring students, that in the aerobics classes only need to allow students to master aerobics can be, and can not think deeply about how to make full use of classroom time, A variety of teaching methods and training methods, in the shortest possible time to train students more aspects of the ability and level, the charm of aerobics as much as possible to carry forward.

Secondly, many aerobics teachers, although conscious of the goal of planning, but like the phased implementation of these teaching objectives, such as one-third of the hours of aerobics basic teaching, one-third of the time to specific Practice, one-third of the class to consolidate and improve, there is no multi-goal planning awareness, the use of classroom time is very inefficient, resulting in students a semester of the course down, in the level of aerobics and no qualitative improvement.

\section{The Importance of Implementing Multi - objective Planning in Aerobics Teaching}

First of all, in the minds of many aerobics teachers are more backward, the goal is set on the existence of the case of broken, tend to use the old set of teaching methods, one by one to teach students aerobics, and then step by step to organize students to practice. However, this teaching method will 
undoubtedly reduce teaching efficiency. Under the multi-objective planning, teachers will be different goals into the same stage of aerobics courses, in a short time to improve teaching efficiency, so that students have significantly improved the results.

Second, in a single stage of teaching objectives, teaching content will become more single, in a stage of learning, students learn every class are the same content, it will inevitably produce a sense of exclusion, The loss of interest in aerobics learning, and once the loss of interest in learning, students naturally difficult to devote themselves into the classroom, no matter how teachers put into the teaching work, students are still absent-minded, can not focus on all the boring classroom content Among them. The implementation of multi-objective programming can make the content of the aerobics course in each stage more and more comprehensive, the use of teaching methods are more abundant, in such an environment, students interest can be effectively excited, And thus actively in the world of aerobics continue to explore.

\section{Design of Aerobics Course Based on Multi - objective Programming}

With the advent of the national fitness era, physical exercise has become an indispensable part of the mass life of our country. As a school, the establishment of aerobics courses can effectively attract students' interest in sports courses that require a lot of physical strength. Students through aerobics to understand sports, to understand sports, healthy exercise, for the community to develop physical fitness and cultural quality of the comprehensive talents. Multi-objective parallel aerobics teaching requires teachers to be able to flexibly use a variety of teaching methods, according to the different teaching objectives to take a different teaching methods to achieve the desired teaching results. In the actual teaching, teachers should always adhere to the classroom to teach students, pay attention to the guidance of students, students continue to cultivate self-learning and self-exploration ability, so as to promote the quality of students to improve, improve the comprehensive level of students, The effect and meaning of teaching.

\section{Improve students' aesthetic ability}

In the past, the process of aerobics teaching is often the teacher first through the password to gradually teach the students aerobics, students in the basic control of these actions, and then play music, lead the students to "fill" these music into the rhythm. In fact, the music in the aerobics has a vital position, the existence of music to aerobics beautiful action has been fully demonstrated, but also gave the original only a beautiful action with more emotional power, so aerobics With the soul. And how students will be music and aerobics together, determines the final completion of the quality and level of aerobics, the ability to understand the music beat must be deep enough to be able to aerobics "beauty" vividly play out. In order to better improve the level of students in the music part of the students to improve the aesthetic ability, in teaching, teachers can be music teaching as the first link, the use of the entire course $25 \%$ of the time to play music to lead students to understand phrases, And continue to develop students' ability to beat. In addition, the teacher should be the combination of music and action on the password before teaching, let the students themselves to complete the four eight-action, that is, a section, and then through the intuitive teaching methods of the whole aerobics in the action So that students only need to remember the number of eight movements of each action can be a complete set of music with the action, do not need the gradual guidance of teachers, greatly enhance the efficiency of teaching, but also improve the students on the The ability to understand music and aesthetic ability, so that students in the aerobics classroom to gain more. In addition, teachers can also "use the needle" in the use of music in teaching, for example, you can rest in the class when playing different styles and rhythmic aerobics music, although the students often break in groups Chat and play, not too much attention to the music being played, but these concerts in the subtle influence given to students, so that students in the quietly appreciate the deepening of the understanding of music. 


\section{Consolidate students' basic ability}

Many aerobics teachers believe that the basic ability of students should be in contact with aerobics, in the initial class time to complete the training, and then the courses are stage to improve and new action training. In fact, the consolidation of the basic competencies of students should penetrate each section of aerobics courses, only the continuous consolidation of the basic ability to be able to make students steadily, take a good way to learn aerobics every step. Teachers can use the multimedia teaching equipment in the daily training in the mirror next to the students play aerobics teaching video, so that students follow the video, facing the mirror to learn from the action. By observing the mirror in their own actions and video in the action of the difference, to find their own actions in the lack of guidance under the guidance of teachers in the wrong action for timely correction and targeted intensive training. This practice can not only enable students to strengthen the study of specific aerobics, but also through their own continuous reflection and correction to continue to strengthen their basic skills, this way, than the teacher directly pointed out that the student's inadequacies more effective.

\section{Cultivate students' ability to collaborate}

Collective gymnastics is a very important part of aerobics, through the regular, planned aerobics teaching to enhance students' teamwork ability, is an important goal of aerobics teaching. In the actual teaching, teachers can be divided into groups according to basic skills and interest in aerobics. Students in each group are kept at 4-6, and each group organizes each team through teamwork. Eight beat the self-action. Teachers should first put forward the requirements of their own actions, explain the way of self-action, then let the groups free discussion and arrangement, and finally arrange for each group to show their own actions, and by the teachers of each group's work guide, Pointed out the shortcomings, to give these deficiencies better solution, and highlight the highlights of which. In the discussion, arrangement, performance, improve the whole process, students on the one hand their own aerobics in the advantages and disadvantages of a more clear understanding of the team to experience the importance of teamwork in aerobics, and profound Perceived the value of their own in the collective; the other hand, the students' creative ability and practical ability also in this process has been vividly played, the students interest in aerobics will continue to increase.

\section{Expand students' learning horizons}

Expand the student vision, so that students access to more knowledge of aerobics, aerobics in the field of understanding of the latest trends and industry trends is to improve the comprehensive ability of students aerobics an important means to enable students to the most intuitive perspective of the latest teaching method. Teachers should actively lead students out of the classroom, so that students see more, learn more. First of all, the teacher can lead the students to the health club, to observe the professional aerobics coach teaching site, and let some interested in after graduation engaged in aerobics related work students more intuitive and close feeling in the classroom Aerobics knowledge, how to use in the workplace; Second, teachers can pay attention to provincial, city, and even national aerobics competition trends, to encourage students to participate in aerobics competition, through the game's high-intensity exercise so that students in the short Time on the aerobics have a more profound understanding of the level of aerobics has been greatly improved. Teachers can also organize student channels aerobics competition scene to watch, learn the game players in the action arrangement, collaboration skills and other aspects of the flash, so that students get first-hand information in the field of aerobics, and into their own learning to go; Finally, the teacher can lead students to work with their neighbors and friends to carry out aerobics activities, so that students of different schools around the aerobics to discuss and communicate enthusiastically, exchange their own knowledge, to show their skills, while making friends at the same time Learn from each other, to achieve the desired teaching effect. 


\section{Enhance students' physical fitness}

Different students learn the purpose of aerobics are not the same, but through the aerobics to enhance the physical quality, is that every student can learn from the aerobics of the harvest. Teachers should pay attention to aerobics in the exercise of the physical quality of students in the daily teaching, do not blindly ask students to "fine jump", but to encourage students to "healthy jump." In order to achieve the goal of enhancing the physical quality of students, on the one hand, teachers can take the students after a semester of aerobics to learn the physical quality of the situation as a test items included in the total score of students, to encourage students to use aerobics exercise, On the other hand, teachers can arrange the way for students to guide students in the spare time to jump aerobics in the form of exercise, the aerobics of the influence extended from the classroom to life, in the bit by bit To enhance the physical quality of students, and promote the comprehensive development of students.

\section{Conclusions}

In short, multi-objective planning under the aerobics teaching is diversified, students in such a teaching environment to better play self-worth, to achieve a comprehensive improvement in the overall quality of the individual, aerobics can also maximize the value of the play The In the future practice, aerobics teachers must adhere to the teaching in a variety of teaching objectives and parallel model, and according to the development of students continue to adjust the existing teaching plan, in response to "quality education", "health first "The call.

\section{References}

[1] Yu Guibo, The Teaching Objectives and Teaching Content of Aerobics in Middle School, Success: Education, 2013(11):278.

[2] Wu Lan, The Problems and Countermeasures of Aerobics Teaching in Secondary, Contemporary Sports Science and Technology, 2012(28):31-33.

[3] Xu Wenli, On the Benefit of Aerobics Teaching to Students in Vocational Secondary Schools, New curriculum: mid, 2012 (11):110.

[4] Li Jing, The Present Situation and Teaching Optimization of Aerobics Teaching in Sports Specialty of Secondary Vocational Education, Arts \& Crafts \& Technology, 2012(12):126.

[5] Deng Xinghua. Cultural Diversification and the Independent Choice of Modern Sports Development. Journal of Beijing Sport University, 2005, 28(3):299- 302. 